\title{
Gestación con éxito en una paciente con anemia y plaquetopenia en programa de hemodiálisis a través de catéter
}

\author{
Victoria Eugenia Muñoz García* - Ana María Vaca Ruiz* - Juana García Criado* - Nayet Mohamed Maanan* \\ Isabel Rosa Fortes** - Victoria García Salas**
}

* D.U.E - **Aux. Enfermería - Hospital Comarcal de Melilla

\section{Introducción}

A pesar de la reducida probabilidad de fertilidad que se da en personas que se dializan, que es dos 0 tres veces superior en mujeres en tratamiento con hemodiálisis que en diálisis peritoneal; y asociada esta infertilidad a un cúmulo de factores; incluyendo, perdida de libido, anovulación y un medio hormonal alterado; a veces ocurre el milagro de la vida.

Incluso en mujeres sanas se presentan patologías propias del embarazo que comprometen la vida de la madre y el niño ${ }^{1}$. Las mujeres que requieren diálisis crónica como tratamiento sustitutivo de la función renal no están exentas de estos riesgos, agregándoseles los factores comorbidos propios de su condición nefrológica:

1. La hipertensión arterial severa, que es la complicación materna más común.

2. La anemia severa, es otra complicación importante que suele precisar aumento de la dosis de eritropoyetina (EPO), hierro e incluso transfusiones sanguíneas.

3. El riesgo de infección; más aún si la paciente es portadora de catéter.

4. La trombopenia gestacional, que es la principal causa de trombopenia en el embarazo; la patogenia de la trombopenia no es del todo conocida, pero parece ser que refleja los efectos de la hemodilución, o bien, una aceleración del aclaramiento de las plaquetas a través del sistema inmune o por mecanismos no inmunes. ${ }^{2}$

$$
\begin{gathered}
\text { Correspondencia: } \\
\text { Victoria Eugenia Muñoz García } \\
\text { Hospital Comarcal de Melilla } \\
\text { Calle Julio Verne 68. Edificio Florencia 1B } \\
52005 \text { MELILLA } \\
\text { vickymuga@hotmail.com }
\end{gathered}
$$

5. El riesgo de sangrado; en general, el riesgo de sangrado suele ser por encías, nariz, hematomas etc. EI tratamiento depende de la causa, siendo importante el control plaquetario. A la hora del parto es importante mantener las plaquetas por encima de 50.000, si es necesario se debe transfundir concentrados de plaquetas.

La investigación de factores protomboticos, la mejoría de la técnica dialítica, el uso de mayor dosis de diálisis, el adecuado control gestacional en centros con experiencia en embarazos de alto riesgo, y la prevención y el tratamiento de las complicaciones maternas pueden tener alguna incidencia sobre la evolución del embarazo (uso de EPO, manejo de la hipertensión arterial, anticoagulación optima, búsqueda y tratamiento precoz de las infecciones y cuidado nutricional con suplementos recomendados), podrán ayudar a mejorar los resultados de los embarazos en diálisis. El régimen intensivo de hemodiálisis está basado en la supervivencia del Recién Nacido, por lo tanto, en el puerperio de debe administrar el régimen dialítico pregestacional.

En los últimos años la supervivencia infantil ha mejorado debido al control y tratamiento dialítico más intensivo, a pesar de esto, la prematuridad es superior al $80 \%$ con edad gestacional media de 32 a 33 semanas y finalización de la gestación mediante cesárea en las dos terceras partes, generalmente por hipertensión y preeclampsia ${ }^{3}$.

Presentamos un caso de una paciente con IRC en programa de HD que concluyó con éxito y sin complicaciones graves para la madre y la niña. La excepcionalidad de este caso radica en varios hechos: que se haya producido en una paciente en programa de hemodiálisis, la anemia y plaquetopenia severa que presentaba la madre, y que ésta era portadora de un catéter temporal que fue sustituido durante el embarazo por un catéter permanente. 


\section{DESCRIPCIÓN DEL CASO}

Paciente de 31 años de edad que desde noviembre de 2006 está en tratamiento sustitutivo de la función renal por Insuficiencia Renal Crónica Hereditaria sin filiar. Portadora de un catéter temporal en femoral izquierda que posteriormente es sustitutido por un catéter permanente en yugular derecha.

Se queda embarazada, a pesar de la reducida probabilidad de fertilidad. Fue diagnosticada por analítica de sangre, la fecha de su última regla fue el 1/1/2007 y la fecha probable de parto fue el $2 / 11 / 2007$. Tras la orientación del nefrólogo proporcionándole información acerca de la situación y de los riesgos de su nuevo estado, decide seguir adelante con su embarazo.

La paciente presentaba anemia, que se intentó corregir con aumento de la dosis de EPO, comenzando con 2.000 u.i. una vez a la semana y finalizando con 10.000 u.i. 3 veces a la semana. Después del parto se le administró EP0 30.000 u.i. 3 veces a la semana. No hay publicaciones acerca de los efectos adversos de la EPO en el embarazo, normalmente se incrementa del $50-100 \%$ la dosis durante el mismo. La ferremia y los niveles de ferritina habitualmente disminuyen, y la falta de hierro puede ser la causa de anemia en los estadios finales del embarazo ${ }^{4}$. Hay dudas sobre la toxicidad aguda del hierro en el feto, por lo que se aconseja minimizar la dosis diaria. El ácido fólico es necesario para el incremento de la hematopoyesis materna y para la adecuada maduración del tubo neural fetal. En nuestro caso se administró hierro una ampolla semanal.

El beneficio de la hemodiálisis diaria o intensiva en el embarazo se ha sugerido en muchas ocasiones, pero su valor para mejorar los resultados de las gestaciones no está definido, aunque hay razones teóricas que avalan su uso, ya que hace que mejore la vida del recién nacido, probablemente por la menor exposición del mismo a los productos nitrogenados acumulados, además de que la ganancia de peso de la madre ínter diálisis es menor y el manejo de los volúmenes es más seguro, lo que produciría menor incidencia de insuficiencia útero- placentaria ${ }^{5}$. Nosotros aumentamos la frecuencia de la diálisis; la pauta de heparinización sódica se mantuvo durante todo el embarazo hasta que la paciente presentó metrorragia y a partir de aquí se suspendió. La heparina no atraviesa la barrera placentaria y no es teratogénica, lo cual la hace segura y se indica, si no hay contraindicación, a dosis habituales para evitar la coagulación del circuito. Los parámetros del embarazo fueron consultados con el equipo de obstetricia del Hospital Comarcal de Melilla y con los equipos de Obstetricia de alto riesgo del Hospital Materno Infantil de Málaga.

\section{ESQUEMA DE DIALISIS}

Se cambió la pauta de hemodiálisis de: 4 horas 3 veces a la semana a sesiones de 3:30 horas, descansando jueves y domingos, y después a sesiones de 3:30 horas, exceptuando domingos. El dializador utilizado ha sido el mismo durante todo el embarazo: Arylane $\mathrm{M9}{ }^{\circledR}$ de fibra hueca de poliariletersulfona.

El baño de diálisis estaba compuesto por bicarbonato, calcio 30 y el flujo de baño de $500 \mathrm{ml} / \mathrm{min}$. El flujo de sangre osciló dependiendo del tipo de catéter, teniendo en cuenta que primero tuvo un catéter temporal cuyo flujo osciló entre 200-300 ml/ min. Y después (el 24/04/2007) se implantó un catéter permanente tipo Hickman en yugular interna derecha, cuyo flujo osciló entre 300-350 $\mathrm{ml} / \mathrm{min}$.

\section{INCIDENCIAS DURANTE EL EMBARAZO}

- Hematomas más acentuados en miembros inferiores.

- Epistaxis.

- Sangrado con amenaza de aborto en la semana 11.

- Sangrado vía vaginal en julio y agosto sin causa aparente y precisando en el último mes ingreso hospitalario.

- El 22/8 se suspende heparina por sangrado; realizándose lavados de circuito y filtro en resto de sesiones.

- El 23/8 se produce la coagulación de circuito extracorpóreo y filtro, debido a ausencia de heparina durante toda la sesión.

- Precisó 8 concentrados de hematíes durante la gestación.

- Plaquetopenia moderada - severa, siendo el valor más bajo de 30x1.000 microlitros, en seguimiento por hematología que no precisó de ningún concentrado.

- Hipertensión arterial moderada severa, actualmente con buen control con alfa metil dopa, hidralazina y beta bloqueantes.

- Síndrome de ansiedad ocasional (más frecuente en el último trimestre).

- Cambió de catéter temporal por un catéter permanente. 


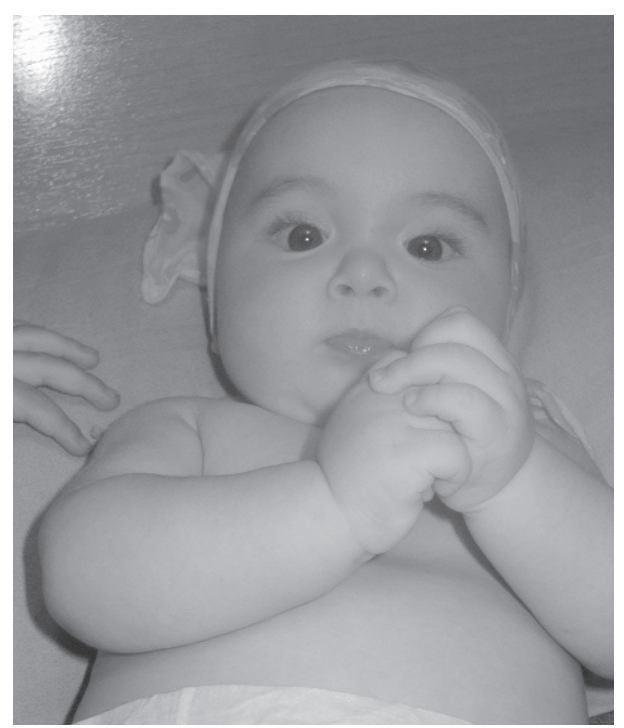

A las 31 semanas de gestación, la paciente dio a luz a una niña, con percentil y morfología correctos y con un peso de $2.000 \mathrm{Kg}$. Por tanto, consideramos que el esquema terapéutico y los cuidados de enfermería que se pautaron a la paciente fueron los adecuados, contribuyendo a llevar a buen término el embarazo.

\section{Bibliografía}

1. Vallejo A. Embarazo en diálisis. Rev Nefrol Dial y Transp 2004; 24 (4):171-8.

2. Diorki, William M, Marshall D. Trastornos médicos durante el embarazo. Madrid: Elseiver España; 2002.

3. Cararach V, Almirall J, Heredia L et al. Hemodiálisis periódica y gestación con feto vivo. Rev Clin e investigación en ginecología y obstetricia 1988; 15 (3): 119-23.

4. Salinas R. Abordaje práctico de las alteraciones hematológicas en la mujer embarazada y en el neonato. Asociación Española de hematología y hemoterapia; 2004.

5. Carretero C, García González A, Gómez Menor C et al. Gestación con éxito en paciente con hipotiroidismo en programa de diálisis. Rev Soc Esp Enferm Nefrol 2006; 9(4): 65-8. 